\title{
Reply to the letter by J. Beco and S. Antolak "Posterior perineal support during defecation, descending perineum syndrome, pudendal neuropathy and anal fissures"
}

\author{
F. Seow-Choen $\cdot$ K. Y. Tan $\cdot$ H. H. Chew $\cdot$ \\ K. T. Gan
}

Received: 18 February 2010/ Accepted: 21 February 2010/Published online: 13 May 2010

(C) Springer-Verlag 2010

Dear Editor,

We read the letter from Drs Beco and Antolak with great interest and would like to thank them for their enthusiasm towards our work [1] and for sharing their experience with us. We had not been previously aware of their publications and this is an example of convergent thinking and discovery.

Our patients with anal fissures who were studied were all suffering from symptoms of anal fissures. However, none had significant or clinically obvious perineal descent. We postulate that patients with strong perineal floor and structures have a limited range of descent movement possible. When this range of elongation is exceeded, the most vulnerable point, which is the posterior anal verge tears. This is possibly why most patients with chronic anal fissure are young and without clinically obvious (as currently defined) perineal descent.
Nonetheless, it would be interesting to see the effect of the Colorec device on patients with clinically obvious perineal descent with the various clincial problems of thus associated. We have been aware of this entity, however, and have been conducting further studies here on this and hope to be able to share further details as these studies mature.

In conclusion, should Drs Beco and Antolak like to collaborate further on this issue, perhaps they would like to contact Dr Chew at hhchew@mechamedic.com for further discussions.

\section{Reference}

1. Tan KY, Seow-Choen F, Hai CH, Thye GK (2009) Posterior perineal support as treatment for anal fissures-preliminary results with a new toilet seat device. Tech Coloproctol 13:11-15 